\title{
Variation in Annual Rainfall Data of Forty Years (1978-2017) for South-South, Nigeria
}

\author{
1,*UKHUREBOR, KE; ${ }^{2}$ ABIODUN, IC \\ ${ }^{I}$ Department of Physics, Edo University Iyamho, Edo State, Nigeria \\ ${ }^{2}$ Department of Physics, Federal University, Otuoke, Bayelsa State, Nigeria \\ *Email: ukhurebor.kingsley@edouniversity.edu.ng; ukeghonghon@gmail.com; +2348035383194
}

\begin{abstract}
In this study the annual rainfall data of forty years (1978-2017) for South-South, Nigeria was collected from the archive of NiMet. Three methods were used for the analysis; statistical differences between two the equal-length time scales, coefficient of variability and the anomaly approach. The trend analysis using $t$-test, Sen's estimator slope and Mann Kendall were also carried out in order to determine the trend in the rainfall variables. The results show that the differences between the two means of the equal-length time scales revealed variability of $7.00 \mathrm{~mm}$. Similarly, the CV of rainfall was 0.145 signifying low variability. However, the anomaly results revealed that 21 years $(52.5 \%)$ recorded less rainfall; while 19 years $(47.5 \%$ ) recorded much rainfall. The Sen's estimator slope revealed downward trend of $94 \mathrm{~mm} / \mathrm{yr}$ in 1978-1987 decades; while it recorded upward trends of; $90 \mathrm{~mm} / \mathrm{yr}, 30 \mathrm{~mm} / \mathrm{yr}$ and $118 \mathrm{~mm} / \mathrm{yr}$ during the $1988-1997$, 1998-2007 and 2008-2017 decades respectively. This study has further revealed that there are variations in the rainfall. Consequently, there is an optimum need to sensitize the general public about its existence in order to take the necessary measures and adaptation options for its mollification and management.
\end{abstract}

DOI: https://dx.doi.org/10.4314/jasem.v22i4.13

Copyright: Copyright (C) 2018 Ukhurebor and Abiodun. This is an open access article distributed under the Creative Commons Attribution License (CCL), which permits unrestricted use, distribution, and reproduction in any medium, provided the original work is properly cited.

Dates: Received: 10 March 2018; Revised: 07April: 2018; Accepted: 21 April 2018

Keywords: Climate; Rainfall; Variation; Homogenous; Statistical package

The seasonal and spatial variations in rainfall to a great extent have effects on agricultural activities as most farmers depend on favorable weather condition to commence their agricultural activities because rainfall plays a crucial role in determining agricultural yields (Ramirez et al., 2003; Audu, 2012; Bhandari, 2013). Variation in rainfall is one of the major features of climate change and variability that could affect the hydrologic characteristics of an area as the water availability can be impaired and could have cruel effects on the entire environment, United Nations Framework Convention on Climate Change (UNFCCC, 2007). Climatic studies are becoming more pertinent because of its impacts in almost every aspects of human existence, (Ukhurebor et al., 2017a, b, c, d). Many researchers including Ogundebi (2004) and Ologunorisa (2004) have alleged intense rainfall to be the main cause of flooding. The increase in flooding as a result of perceived increase in rainfall intensities within the Southern part of Nigeria, is posing enormous risk to lives and properties. According to Ayansina et al., (2009); the seasonal and annual rainfall variability in some parts of Nigeria continues to be on the increase as an element of climate change and variability.

It is predicted by the United Nations Development Programme (UNDP), that the impacts of climate change and variability such as sea-level rise, droughts, heat waves, floods and changes in precipitation, could by 2080 push about 600 million people into food shortages and the number of people facing water scarcities would reached 1.8 billion (UNDP, 2008). Despite potential economic value of having a sizable population, Nigeria like most other African and developing countries of the world appears not to be putting proactive and mitigation measures in place to check climate change (Pat-Mbano and Alaka , 2012), and this certainly is exposing its citizenry to enormous risks and vulnerabilities associated with climate change and variability. This study makes use of the annual rainfall data of forty years (1978-2017) for South-South, Nigeria which was collected from the archive of the Nigerian Meteorological Agency (NiMet) in order to ascertain the rainfall variability and its future trend. The imperative of this study lies in the fact that it is one of the most recent studies to the best of our knowledge from existing literatures on rainfall variability specifically in these parts of Nigeria. It is obvious that through this study the consciousness of the general public will be drawn to the existence of rainfall variability, its future trend and impacts in almost all aspects of human endeavors, particularly in agriculture in order to take the necessary adaptive, management and mollification measures. 


\section{MATERIALS AND METHODS}

Area of Study: South-South Nigeria is one of the six geopolitical zones in Nigeria which comprises of six states (Akwa Ibom, Bayelsa, Cross River, Delta, Edo, and Rivers). The region experiences the humid tropical climate, which is characterized by wet and dry seasons. This region is rich with crude oil which provides the major economic lame stream of the country. It also constitutes a reasonable number of Nigeria's population.

Materials used for the Study: The materials used for this study are monthly rainfall data of forty years (1978-2017) collected from NiMet and statistical Package (IBM SPSS Version 20, Microsoft Excel, MATLAB). The non-parametric Thom's homogeneity test was used for this study. Homogeneity in climate series is said to occur when its variations are caused by changes in weather and climate (Karabulut et al., 2008; Attah, 2013). For $N \geq$ 25 , if the climate series is homogenous, the distribution of the number of runs $(R)$ approximates a normal distribution with the mean $(X)$ and variance, $S(R)$ as:

$$
\begin{aligned}
& X(R)=\frac{N+2}{2} \\
& S(R)=\frac{N(N-2)}{4(N-1)} \\
& Z=\frac{R-E(R)}{\sqrt{S(R)}}
\end{aligned}
$$

For $\alpha=0.01$ level of significance, the null hypothesis $\left(H_{0}\right)$, that the data is homogenous is accepted if $\mid \mathrm{Zl} \leq$ 2.58, otherwise an alternative hypothesis $\left(H_{a}\right)$ is accepted. For $\alpha=0.05$ level of significance, $H_{0}$, that the data is homogenous is accepted if $|Z| \leq 1.96$, otherwise $H_{a}$ is accepted.

Methods Used for the Study: Rainfall data collection and analysis were the methods used for this study. The three methods that were employed in the analysis of the collected rainfall data are Simple Approach, Coefficient of Variability (CV) and Anomaly Approach.

Trend evaluation using parametric and non-parametric methods was also carried out in order to determine the variations in the rainfall variables and ascertain its future trend.

Simple Approach: This method measures the rainfall variability by dividing the climatic time series into two equal periods as recommended by World Meteorological Organization (WMO, 1988). The two equal length time scales used are; 1978-1997 and 1998-2017. The differences between their means $(X)$ and standard deviations $(\boldsymbol{\delta})$ are computed and the climate variability is obtained by Eqns. 5 and 6 accordingly;

$C_{v}=X_{1}-X_{2}$

$C_{v}=\boldsymbol{\delta}_{1}-\boldsymbol{\delta}_{2}$

Where $C_{v}$ is the rainfall variability, $X_{I}$ is the mean of the first time scale, $X_{2}$ is the mean of the second time scale, $\boldsymbol{\delta}_{1}$ is the standard deviation of the first time scale and $\boldsymbol{\delta}_{2}$ is the standard deviation of the second time scale. $X$ and $\boldsymbol{\delta}$ were obtained using;

$$
\begin{aligned}
& \mu=\sum_{i=1}^{n} x i \\
& \delta=\sqrt{\sum_{i=1}^{n}(x i-\mu)^{2}}
\end{aligned}
$$

Where $x_{i}$ is the rainfall variable and $n$ is the sample size. While the statistics for the skewness $\left(g_{1}\right)$ and kurtosis $\left(g_{2}\right)$ were obtained using Eqns. 8 and 9 respectively.

$$
\begin{aligned}
& g_{1}=\frac{\frac{1}{n-1} \sum_{i=1}^{n}(x i-\mu)^{3}}{\delta^{3}} \\
& g_{2}=\frac{\frac{1}{n-1} \sum_{i=1}^{n}(x i-\mu)^{4}}{\delta^{4}}
\end{aligned}
$$

Coefficient of Variability (CV) Approach: This is the second method that was employed in analyzing the rainfall variability for this study. It compares the size of standard deviation relative to the mean of the rainfall variables. It was obtained using Eqn. 10;

$C_{v}=\frac{\delta}{\mu}$

Note: $C_{v}$ value of below $0.1(10 \%)$ indicates low variability, above 0.9 (90\%) reveals high variability; while the climate is stable if $C_{v} \leq 0.4(40 \%)$, after which it becomes unstable (Durdu, 2009; Attah, 2013).

Anomaly Approach: The anomaly approach is the third method used for this study. It enables the determination of rainfalls that are higher than normal (wet) which are designated by positive values and rainfalls lower than normal (dry), designated by negative values. In this method, the average value of the rainfall variables over a period of thirty years was computed. The climate normal (thirty years) used was the mean of 1978-2007, climatic periods as recommended by the Nigerian Meteorological Agency (NiMet, 2010). The anomaly was obtained by subtracting the climate normal from yearly mean of each rainfall variable as shown in Eqn. 11;

$$
A=X_{i}-\mu_{30}
$$


Where $A$ is the anomaly, $\mu_{30}$ is the climate normal and $X_{i \text { is }}$ the average value of the rainfall variable.

The decadal variability of rainfall were obtained by using the deviation of the decadal mean (ten years mean) of the rainfall variable from the climate normal of the rainfall variable as presented in Eqn. 12;

$D_{a}=\mu_{10}-\mu_{30}$

$D_{a}=\frac{\mu 10-\mu 30}{\mu 30} \times 100$

Where $D_{a}$ is the decadal anomaly, $\mu_{10}$ is the decadal mean.

Trend Analysis: Trend analysis was used to determine the change of the random variables during the period under consideration (1978-2017) in statistical terms. The estimate of the magnitudes of the trends in the annual rainfall of the forty years and their statistical significances were obtained. The methods employed in detecting the trend of the rainfall variables were both parametric and non-parametric tests (Longobardi, 2009; Jain and Kumar, 2012; Attah, 2013). The parametric test used is the Student's $t$-test, while the non-parametric tests used were the Mann Kendall and Sen's estimator slope methods (Longobardi, 2009; Karbulut et al., 2008). The non-parametric test is more reliable and better when the distribution data are skewed and it is a function of ranks of the observations. However, unlike the parametric test, non-parametric test it is not affected by the outliers (Oke and Ismai'1, 2012).

Student's t-test: This method was performed by regressing rainfall variable $(y)$ on the time $(x)$. The method assumed a linear trend in the time series. The regression analysis was carried out by considering time as the independent variable, while the annual rainfall as the dependant variables. The general statistical model use to represent linear regression is shown as Eqn. 15 (Jain and Kumar, 2012);

$y_{i}=\boldsymbol{\beta} \boldsymbol{o}+\boldsymbol{\beta} \boldsymbol{x i}+\boldsymbol{\varepsilon i}$

Where $y_{i}$ is the ith observation of the dependant variable (response), $x_{i}$ is the ith value of the independent variable (years), $\boldsymbol{\beta} \boldsymbol{o}$ is the intercept (constant), $\boldsymbol{\beta}$ is the slope of the regression line (trend of the rainfall variables), $\varepsilon \boldsymbol{i}$ is random error. The regression analysis was carried out using IBM SPSS version 20 software. It is expected that the statistics in Eqn. 15 follows student's t-distribution that has $n-2$ degrees of freedom (Longobardi, 2009); $t=\frac{\frac{\beta}{\sum_{i=1}^{n}(y i-Y)^{2}}}{(n-2) \sum_{i=1}^{n}(x-X)^{2}}$

Where $t$ is the student's t value, $\boldsymbol{\beta}$ is the slope (trend), $n$ is the sample size, $y_{i}-Y$ is the error, $X$ is the mean of the independent variable $\mathrm{x}$ and $n-2$ is the degrees of freedom. The term $Y$ is given as;

$Y=\beta o+\beta x i$

$H_{o}$; that the trend in the rainfall variables is not statistically significance is obtained when the computed value of $t$ is less than the critical value. $H_{a}$ is obtained if the calculated value of $t$ is greater than the critical value.

Sen's Estimator Slope: The Sen's estimator slope is applicable for the determination of the extent of the trend in the time series rainfall variable. In this method, the slopes $\left(T_{i}\right)$ of all the data were computed using Eqn.17 (Jain and Kumar, 2012);

$T_{i}=\frac{x \boldsymbol{j}-x \boldsymbol{k}}{\boldsymbol{j}-\boldsymbol{k}}$

Where $i=1,2, \ldots, N$ in which $\mathrm{N}$ is the number of observations, $\boldsymbol{x} \boldsymbol{j}$ and $\boldsymbol{x} \boldsymbol{k}$ are values of the rainfall data at times $\boldsymbol{j}$ and $\boldsymbol{k}$ respectively, for which $(\boldsymbol{j}-\boldsymbol{k})$ The median of these values of $T_{i}$ is regarded as the Sen's estimator slope, which is calculated in Eqn. 18 (Jain, 2012) as;

$\boldsymbol{\beta}= \begin{cases}\frac{T(N+2)}{2} & \text { if } N \text { is odd } \\ 1 / 2(T(N / 2+T(N+2) / 2 & \text { if } N \text { is even }\end{cases}$

If $\beta$ has positive value, it implies an inclining trend, but if negative it implies declining trend in the climatic time series. The statistical significance of the trend is ascertained using the Mann Kendall test.

Mann Kendall Test: This test was used to determine the presence of trend or otherwise in the rainfall variables and the statistical significance of the trend. The Mann Kendall identified the $H_{0}$ of the presence of trend versus the $H_{a}$ that there is no trend. The Mann Kendall test can be applied to non-normal distribution that has seasonality, missing values and unusual data (Attah, 2013; Jain and Kumar, 2012). The rainfall data were divided into four decades; 1978-1987, 19881997, 1998-2007 and 2008-2017. The trends for the rainfall data were then obtained. The Mann Kendall $(S)$ statistics is defined by Jain and Kumar, (2012); Longbardi, (2009); Karabulut, (2008) as;

$$
S=\sum_{i=1}^{n-1} \sum_{j=i+1}^{n} \quad \operatorname{sign}(x j-x i)
$$


Where $\mathrm{n}$ is the number of data points, $x$ is the observed climatic variable, $(\boldsymbol{x} \boldsymbol{j}>\boldsymbol{x i}) \operatorname{taking}(\boldsymbol{x} \boldsymbol{j}-\boldsymbol{x} \boldsymbol{i})=\boldsymbol{\theta}$, the value of $\operatorname{Sign}(\boldsymbol{\theta})$ was calculated by;

$\operatorname{Sign}(\theta)=\left\{\begin{array}{cc}+\mathbf{1} & \text { if } \theta>0 \\ \mathbf{0} \quad \text { if } \boldsymbol{\theta}=0 & \mathbf{0} \\ -\mathbf{1} & \text { if } \theta<0\end{array}\right.$

The $\mathrm{Z}$ statistics was estimated using (Jain and Kumar, 2012; Longbardi, 2009; Karabulut, 2008) Eqn. 21;

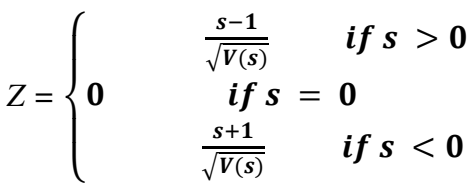

Where the variance, $V(s)$ is calculated using Eqn. 22;

$V(s)=\frac{n(n-1)(2 n+5)-\sum_{q=1 t q}^{p}(t q-1)(2 t q+5)}{18}$

Where $p$ is the number of tied groups (zero differences between the compared values of the rainfall data), $t q$ is the number of the data points in the $q$ th tied group. $H_{0}$ is rejected and $H_{a}$ is accepted if the calculated value of $\mathrm{Z}$ $>Z_{\propto / 2}$ at $\propto$ level of significance, otherwise $H_{0}$ is accepted and $H_{a}$ rejected at $\propto=0.05, Z_{\propto / 2}=1.96$ and at $\propto=0.01, Z_{\propto / 2}=1.65$ (Attah, 2013; Jain and Kumar, 2012).

\section{RESULTS AND DISCUSSION}

Homogeneity Test: The homogeneity test performed on the rainfall variables used for this study is shown in Table 1. The data homogeneity test is important in identifying the reliability as well as the suitability of the time series data for climate change and variability studies (Toumenvirta, 2002).

Table 1: Homogeneity Test for Climate Variables

\begin{tabular}{cc}
\hline & Rainfall Data \\
\hline$Z$-value & $1.60^{*}$ \\
\hline
\end{tabular}

$Z$-value is significant at $\alpha=0.05$ : This shows that the annual rainfall during the forty years (1978-2017) under investigation were homogenous. The $Z$-statistics is also shown in Table 1, in which the result signified that, the homogeneity of the rainfall variables were statistically significant at $95 \%$ confidence level as the computed $Z$-value was less than 1.96. This ascertained that the rain variables used for this study were good and reliable for climate change and variability studies.

Variations in the Annual Rainfall Variables: The annual variations in the rainfall during the forty years (1978-2017) under investigation are presented in
Figures 1. It is shown that there were variations in the sense that some years recorded higher values of the rainfall values than other years.

It was observed that 1985 recorded the highest rainfall value of $1349 \mathrm{~mm}$; while, 1990 recorded the lowest rainfall value of $686 \mathrm{~mm}$. This revealed that there were variations in the rainfall. The variations in rainfall (both seasonal and spatial) to a great extent have effects on agricultural activities as most farmers depend on favorable weather condition to commence their agricultural activities and this also play a crucial role in determining agricultural yields (Bhandari, 2013; Audu, 2012). It also has effects on other human activities. The implication of heavy rainfall events is evident in the destruction of plants, soil erosion, difficulty in cultivating land due to water logging of soils, Intergovernmental Panel on Climate Change (IPCC, 2007), and this could also lead to environmental hazard.

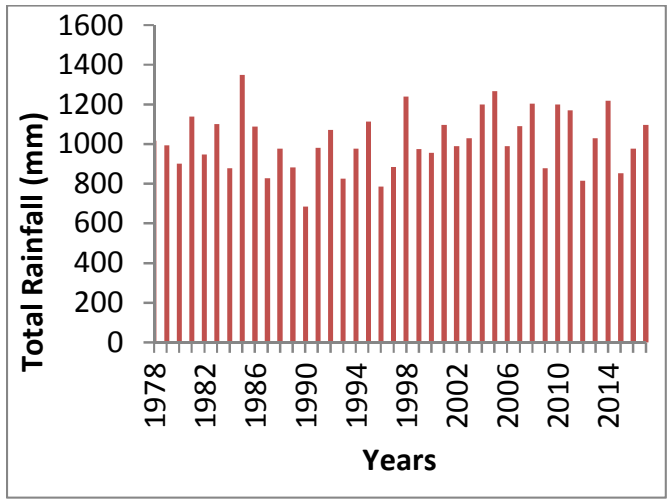

Fig. 1: Annual Total Rainfall Variations

Descriptive Statistics of the Climatic Variables: The statistical parameters used for the descriptive statistics of the rainfall variables during the forty years (19782017) under investigation which is presented in the Table 2 are; maximum (Max), minimum (Min), mean $(X)$, median $($ med $)$ and standard deviation $(\boldsymbol{\delta})$.

Table 2: Descriptive Statistics of the Climatic Variables

\begin{tabular}{cc}
\hline Statistical parameters & Rainfall $(\mathbf{m m})$ \\
\hline Max & 686 \\
Min & 1349 \\
X & 1018 \\
med & 992 \\
$\boldsymbol{\delta}$ & 148 \\
\hline
\end{tabular}

It was observed that the annual rainfall recorded the Max of $1349 \mathrm{~mm}$ and Min value of $686 \mathrm{~mm}$, with the corresponding $X$, med and $\boldsymbol{\delta}$ of; $1018 \mathrm{~mm}, 992 \mathrm{~mm}$ and $148 \mathrm{~mm}$, respectively. As reported by Bhandari, (2013) and Ramirez et al., (2003), the variations of 
climatic variables have great consequences on reliable agriculture.

Variability of the Rainfall Variables: The variability of the rainfall variables used for this study for the period under consideration is shown in Table 3. The variability was in terms of the differences between the means, standard deviations, coefficient of variability, skewness and kurtosis of two the equal-length time scales of 1978-2007 and 1998-2017 respectively. The overall (1978-2017) mean $(X)$, standard deviation $(\boldsymbol{\delta})$, coefficient of variability $(C V)$, skewness $\left(g_{1}\right)$ and kurtosis $\left(g_{2}\right)$ are also shown in Table 3.

Table 3: Variability of the Climatic Variables

\begin{tabular}{ccc}
\hline Statistical Parameters & Periods & Rainfall \\
\hline $\boldsymbol{X}$ & $1978-2017$ & 1018.000 \\
& $1978-2007$ & 1009.000 \\
& $1988-2017$ & 1016.000 \\
& Variability & -7.000 \\
$\boldsymbol{\delta}$ & $1978-2017$ & 148.000 \\
& $1978-2007$ & 147.000 \\
& $1988-2017$ & 149.000 \\
$\boldsymbol{C} \boldsymbol{V}$ & Variability & -2.000 \\
& $1978-2017$ & 0.145 \\
& $1978-2007$ & 0.145 \\
& $1988-2017$ & 0.146 \\
$\boldsymbol{g}_{\boldsymbol{1}}$ & Variability & -0.001 \\
& $1978-2017$ & 0.072 \\
& $1978-2007$ & 0.196 \\
& $1988-2017$ & -0.164 \\
$\boldsymbol{g}_{\mathbf{2}}$ & Variability & 0.360 \\
& $1978-2017$ & -0.363 \\
& $1978-2007$ & 0.248 \\
& $1988-2017$ & -0.593 \\
& Variability & 0.841 \\
\hline
\end{tabular}

It was shown that the rainfall variables recorded some level of variability using the differences between the means of the equal-length time scales of 1978-2007 and 1998-2017 of $-7 \mathrm{~mm}$. The negative sign implies that the mean of base line first time scale for 19782007 is lower than the mean of the second time scale for 1998-2017; which signifies rainfall variability. However, using the differences between the standard deviations of the equal-length time scales of the rainfall variables, the variability of $-2 \mathrm{~mm}$ was obtained. On the other hand, the CVs of the rainfall variables using the time scales of 1978-2007 also recorded some changes. The values was $0.145(14.5 \%)$ respectively; while for the 1998-2017 time scale, the CVs was $0.146(14.6 \%)$, respectively. The overall coefficient of variability was 0.145 (14.5\%); signifying low variability.

Similarly, the differences in the skewness of the two equal-length time scales was 0.360 ; while the differences in the kurtosis of the two equal-length time scales was 0.841 , signifying that the rainfall variables were skewed. Furthermore, the analysis of the distribution of the historic data (skewness) for the 1978-2017 showed that rainfall had the positive values of 0.072 ; signifying that they were right skewed and this is in agreement with the work of Attah, (2013) and NiMet observation of the late onset of and early cessation of rainfall since 1911. This will definitely have effects on the hydrologic characteristics of the area as the water availability, (Ayansina et al., 2009), as such other environmental consequences will be inevitable.

Anomalies of the Rainfall Variables: In order to ascertain the deviations in the rainfall variables from the established normal climate for the period under investigation (1978-2017), the anomaly of the rainfall variables were computed and is shown in Figure 2.The established normal for rainfall was $1009 \mathrm{~mm}$; any deviation from this established normal climate signifies rainfall variability.

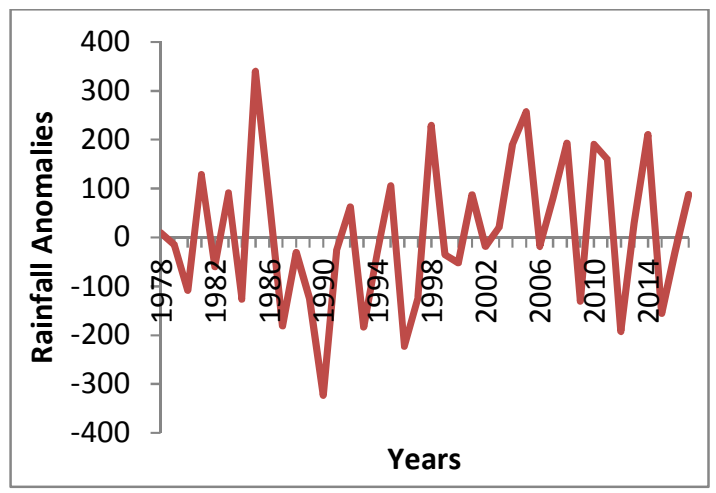

Fig. 2: Annual Rainfall Anomalies

The line corresponding to zero is the base line, which signifies the average rainfall of thirty years and the normal rainfall value of $1009 \mathrm{~mm}$. The base line as can be observed in the figure is the line that correspond to zero and it is the average rainfall record of thirty years which also implies the normal rainfall $(1009 \mathrm{~mm})$. The positive values (above zero) signify rainfalls that were higher than normal (wet); while the negative values (below zero) imply rainfalls that were lower than normal (dry). It is observed that 19 years representing $47.5 \%$ recorded wet due to the fact that the rainfalls that occurred in those years were greater than the normal rainfall; while 21 years representing $52.5 \%$ recorded dry due to the fact that the rainfalls that occurred in these years were below normal rainfall.

Decadal Variability of the Rainfall Variables: The decadal variability for rainfall for the period under consideration (1978-2017) is presented in Table 4. The 
decadal mean and percentage changes are also contained in the Table accordingly.

Table 4: Decadal Variability of Rainfall

\begin{tabular}{cccc}
\multicolumn{4}{c}{ Table 4: Decadal Variability of Rainfall } \\
\hline Decade & $\boldsymbol{\mu}_{\mathbf{1 0}}(\mathbf{m m})$ & $\boldsymbol{\mu}_{\mathbf{1 0}-} \boldsymbol{\mu}_{\mathbf{3 0}}(\mathbf{m m})$ & $\begin{array}{c}\text { Percentage } \\
\text { Change (\%) }\end{array}$ \\
\hline $1978-1987$ & 1024 & 15 & 1.50 \\
$1988-1997$ & 920 & -89 & -8.80 \\
$1998-2007$ & 1083 & 74 & 7.30 \\
$2008-2017$ & 1045 & 36 & 3.60 \\
\hline
\end{tabular}

The Table shows the decadal variability of the rainfall, the decadal mean and percentage changes in the rainfall accordingly, using the established normal rainfall of $1009 \mathrm{~mm}$. The positive sign signifies much rainfall (wet); while the negative sign signifies less rainfall (dry) for the particular decade under consideration. It was observed that three decades (1977- 1987, 1998-2007 and 2008-2017) representing $75 \%$ were associated with much rainfall; while the remaining one decade (1988-1997) representing $25 \%$ was having less rainfall. The result affirm the report of Attah, (2013); that the rainfall in lower Kaduna catchment, Nigeria increased by $100 \mathrm{~mm}$ per decade from 1971-2006.

Trend Analysis: Parametric Test: The results of the regression and the corresponding $t$-test results of rainfall for the period under consideration (1978-2017) are contained in Tables 5 and 6 respectively.

The slope of the regression of the rainfall variables represents the trend.

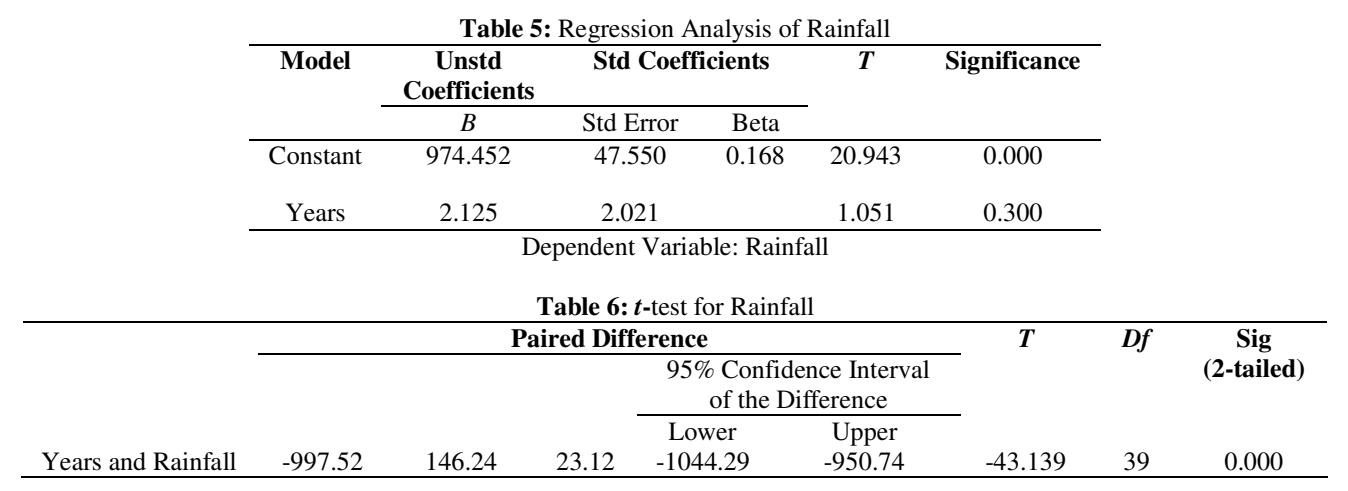

Non Parametric Test: The Sen's estimator slope of the annual rainfall for the period under investigation is shown in Table 7.

\begin{tabular}{cc} 
Table 7: Sen's Estimator Slope of the Rainfall Variables \\
\hline Periods & Trends of Climatic Variables \\
\cline { 2 - 2 } & Rainfall (mm/yr) \\
\hline $1978-1987$ & -94.0 \\
$1988-1997$ & 90.0 \\
$1998-2007$ & 30.0 \\
$2008-2017$ & 118.0 \\
\hline
\end{tabular}

Table 8: Mann Kendall of the Rainfall Variables

\begin{tabular}{ll}
\hline & \multicolumn{1}{c}{ Rainfall Variables } \\
\hline Periods & $1978-1987$ \\
Mann Kendall & -3.000 \\
Z-statistics & -0.179 \\
Periods & $1988-1997$ \\
Mann Kendall & 1.000 \\
Z-statistics & 0.000 \\
Periods & $1998-2007$ \\
Mann Kendall & 1.000 \\
Z-statistics & 0.000 \\
Periods & $2008-2017$ \\
Mann Kendall & 1.000 \\
Z-statistics & 0.000 \\
\hline
\end{tabular}

It is observed that the rainfall recorded a downward trend of $-94 \mathrm{~mm} / \mathrm{yr}$ during 1978-1987 decade, while there were upward trends of $90 \mathrm{~mm} / \mathrm{yr}, 30 \mathrm{~mm} / \mathrm{yr}$ and $118 \mathrm{~mm} / \mathrm{yr}$ for the remaining three other decades (1988-1997, 1998-2007 and 2008-2017) respectively. The Mann Kendall test was carried out to further ascertain the trend in the rainfall variables and also to determine its statistical significance using the $Z$ statistics. The Mann Kendall test for the annual rainfall is shown in Table 8.

It was observed that the annual rainfall recorded Mann Kendall of -3.0, 1.0, 1.0 and 1.0 during 1978-1987, 1988-1997, 1998-2007 and 2008-2017 decades respectively. This signified a downward trend in the 1978-1987 and upward trends in 1988-1997, 19982007 and 2008-2017 periods, but they are not statistically significant at $95 \%$ confidence level as the computed $Z$-value is $<1.96$. This result shows that the area recorded upward trend in rainfall during the last three decades, signifying that the area is becoming to have more rainfall which will definitely affect the hydrologic characteristics of the area and possibly have vicious effects on the entire environment as it is be noticed already.

Conclusion: This study has revealed that rainfall variability is noteworthy, so there is an optimum need 
to sensitize the general public about its existence in order to take the necessary measures and adaptation options for its mollification and management, because of its influence on agricultural activities and other aspects of human lives. Conclusively, it is recommended that further studies on climate variability should be carried out specifically in other parts of the country considering more weather variables, such as wind speed, atmospheric pressure, relative humidity, temperature, etc.

Acknowledgement: The authors are grateful to the Nigerian Meteorological Agency (NiMet) for their assistance.

\section{REFERENCES}

Attah, DA (2013). Climate Variability and its Impact on Water Resources of Lower Kaduna Catchment. Unpublished PhD Thesis, Department of Water Resources and Environmental Engineering, Ahmadu Bello University, Zaria, Nigeria.

Audu, EB (2012). A Descriptive Analysis of Rainfall for Agricultural Planning in Lokaja Local Government Area of Kogi State, Nigeria. Inter. J. Sci. Technol. 2(2), 850-854.

Ayansina, A; Ogunbo, S (2009). GIS Approach in Assessing Seasonal Rainfall Variability in Guinea Savanna Part of Nigeria. 7th FIG Regional Conference, Vietnam.

Bhandari, G (2013). Effect of Precipitation and Temperature Variation on the Yield of Major Cereal in Dadeldhura District of far Western Development Region, Nepal, International. J. Plant Animal Environ. Sci. 3(1) 247-255.

Durdu, OF (2009). Effects of Climate Change on Water Resources of the Buyuk Menderes River Basin, Western Turkey. J. Agric. 34. 319-332.

IPCC (2007). Climate Change Impacts, Adaptation and Vulnerability. Contribution of the working group II to the Fourth Assessment Report of the Intergovernmental Panel on Climate Change, Cambridge University Press, United Kingdom.

Jain, SK; Kumar, V (2012). Trend Analysis of Rainfall and Temperature Data for Indian. Review Article. Current Sci.102 (1).

Karabulut, M; Gurbuz, M; Korkmaz, H (2008). Precipitation and Temperature Trend Analysis in Samsun. J. Inter. Environ. Applica. Sci. 3(5), 399408.
Longobardi, A; Villari, P (2009). Trend Analysis of Annual and Seasonal Rainfall Times Series in the Mediteranian Area. Inter. J. Climatol. Royal Meteorol. Soc.

NiMet (2010): Nigeria Climate Change Review Bulletin, Nigeria Meteorological Agency. (http://www.nimetng.org).

Oke, IA; Ismai'l, A (2012). Trend Analysis of Precipitation in BirninKebbi, Nigeria.International Res. J. Agric. Sci. Soil Sci., 2(7), pp 286-297.

Ogundebi, AO (2004). Socio-economic impacts of Flooding in Lagos State. Environ. Impact Anal. 12 (1), 16-30.

Ologunorisa, ET (2004). Rainfall Flood Prediction in the Niger Delta, Nigeria. (Abstract), International Conference in Hydrology; Science and Practice for the 21st Century, London, U.K.

Pat-Mbano, EC; Alaka, IN (2012). Climate Change Reduction; A Mirage in Nigeria. Manage. Sci. Engineer. 6(1) 11-17.

Ramirez, D; Ordaz, JL; Mora, J; Acosta, A; Serna, B (2003). Belize Effect of Climate Change on Agriculture. Department for International Development, United Nations.

Rasul, G; Chaudhry, QZ; Mahmood, A; Hyder, KW (2014). Effect of Temperature Rise on Crop Growth and Productivity. Pakis. J. Meteorol. 8(15): 53- 62 .

Tuomenvirta, H (2002). Homogeneity Testing and Adjustment of Climatic Time Series in Finland. $J$. Geophysic. 38(1-2): 15-41.

Ukhurebor, KE; Abiodun, IC; Bakare, F (2017a). Relationship between Relative Humidity and the Dew Point Temperature in Benin City, Nigeria. $J$. Appl. Sci. Environ. Manage. 21(5) 953-956.

Ukhurebor, KE; Batubo, TB; Abiodun, IC; Enoyoze, E (2017b). The Influence of Air Temperature on the Dew Point Temperature in Benin City, Nigeria. J. Appl. Sci. Environ. Manage.21(4), 657-660.

Ukhurebor, KE; Abiodun, IC; Azi, SO; Otete, I; Obogai LE (2017c). A Cost Effective Weather 
Monitoring Device. Archives of Current Res. Inter.7 (4) 1-9.

Ukhurebor, KE; Azi, SO; Abiodun, IC; Enoyoze, E (2017d). Approximation of the Dew Point Temperature Using a Cost Effective Weather Monitoring System. Phys. Sci. Inter. J. 14(3), pp 1-6.

UNDP (2008). Fighting Climate Change, Human Solidarity in a Divided World. Human Development Report, United Nations
Development Programme, New Work, 10017, U.S.A.

UNFCCC (2007). Climate Change Impact, Vulnerabilities and Adaptation in Developing Countries. United Nations Framework Convention on Climate Change, Information Services of UNFCCC Secretariat, Germany.

WMO (1988). Analyzing Long Time Series of Hydrological Data with respect to Climate Variability. World Meteorological Organization, TD-NO.224. 